\title{
Effect of Ag nanoparticles integrated within antireflection coatings for solar cells
}

F. Cortés-Juan, C. Chaverri Ramos, J. P. Connolly, C. David, F. J. García de Abajo et al.

Citation: J. Renewable Sustainable Energy 5, 033116 (2013); doi: 10.1063/1.4808259

View online: http://dx.doi.org/10.1063/1.4808259

View Table of Contents: http://jrse.aip.org/resource/1/JRSEBH/v5/i3

Published by the American Institute of Physics.

\section{Additional information on J. Renewable Sustainable Energy}

Journal Homepage: http://jrse.aip.org/

Journal Information: http://jrse.aip.org/about/about_the_journal

Top downloads: http://jrse.aip.org/features/most_downloaded

Information for Authors: http://jrse.aip.org/authors

\section{ADVERTISEMENT}
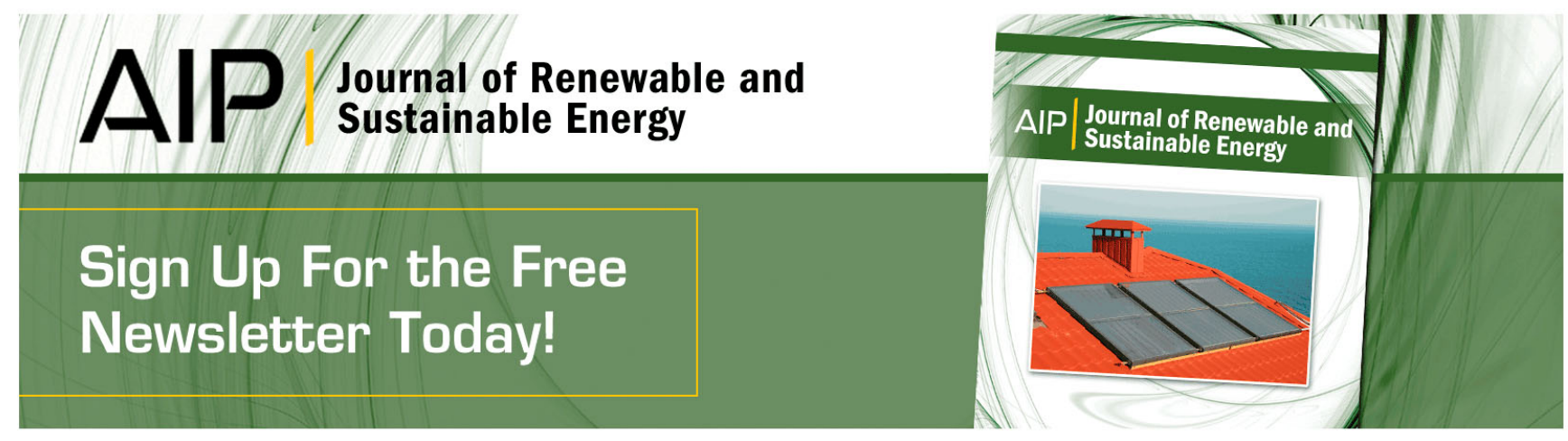


\title{
Effect of Ag nanoparticles integrated within antireflection coatings for solar cells
}

\author{
F. Cortés-Juan, ${ }^{1, a)}$ C. Chaverri Ramos, ${ }^{1}$ J. P. Connolly, ${ }^{1}$ C. David, ${ }^{2}$ \\ F. J. García de Abajo, ${ }^{2}$ J. Hurtado, ${ }^{1}$ V. D. Mihailetchi, ${ }^{3}$ S. Ponce-Alcántara, ${ }^{1}$ \\ and Guillermo Sánchez ${ }^{1}$ \\ ${ }^{1}$ Valencia Nanophotonics Technology Center, Edificio 8F, Universitat Politécnica de \\ Valéncia, Camino de Vera s/n, 46022 Valencia, Spain \\ ${ }^{2}$ Insituto Química-Física “Rocasolano," Consejo Superior de Investigaciones Científicas, \\ Serrano 119, 28006 Madrid, Spain \\ ${ }^{3}$ International Solar Energy research Center (ISC), Rudolf-Diesel-Str.15, \\ D-78467 Konstanz, Germany
}

(Received 6 February 2013; accepted 17 May 2013; published online 30 May 2013)

\begin{abstract}
The influence of the relative position of $\mathrm{Ag}$ metallic nanoparticles (Ag MNPs) embedded in a $100 \mathrm{~nm} \mathrm{SiO}_{\mathrm{x}}$ Antireflection Coating (ARC) for specular polished c-Si substrates is studied. It is demonstrated that this Plasmonic ARC (PARC) can achieve lower average reflectivities than the optimised $\mathrm{SiO}_{\mathrm{x}} \mathrm{ARC}$. This has been done for different sizes of $\mathrm{Ag}$ nanoparticles. An alternative for PECVD to encapsulate $\mathrm{Ag}$ MNPs with $\mathrm{SiO}_{\mathrm{x}}$ is presented, avoiding the risk of metallic contamination in the reactor chamber as well as its effect on the size and shape of the self-aggregated Ag MNP. It is demonstrated, however, that this PARC is not suitable for silicon solar cells as a substitute for traditional ARC because it presents a high loss related with Fano destructive interference. (C) 2013 AIP Publishing LLC. [http://dx.doi.org/10.1063/1.4808259]
\end{abstract}

\section{INTRODUCTION}

In recent years, plasmonic particle layers (PPLs) made up of metal nanoparticles have been extensively studied as a way of improving solar cells. ${ }^{1-3}$ Nanoparticles can efficiently scatter light ${ }^{4-6}$ thereby increasing the optical path length of the incident light. Light coupling into the solar cell structure may be further enhanced if the PPL results in a high density of optical modes. This enables efficient thin film technology $\mathrm{y}^{7-10}$ and furthermore increases the absorption efficiencies of standard cells.

Specific efforts have been made to incorporate Ag nanoparticles as Ag PPLs since Ag has relatively low absorbance in the wavelength range of interest. ${ }^{6}$ In the most cost effective methods, Ag metallic nanoparticles (MNPs) are obtained chemically or by auto-aggregation of thin Ag layers. ${ }^{11,12}$ The first method can be applied to solar cells by spin coating. ${ }^{13,14}$ It has recently been proposed that the resulting material matrix incorporating Ag MNPs can be optimized as antireflective coating (ARC). ${ }^{11,15-17}$ This type of structure usually shows an aging of Ag PPL ${ }^{18}$ and therefore some authors have proposed the addition of a protective layer to avoid the degradation. ${ }^{19}$

The optical response of the resulting system of PPL and enclosing matrix requires careful optimization in order to maximise light interaction with the underlying solar cell. Of particular importance is the separation between the PPL and the substrate, and consequences for Fano ${ }^{20}$ interference losses between scattered and incident light. The following work presents a study of the reflectivity of different Ag PPLs as a function of the position of the Ag PPL within a $\mathrm{SiO}_{\mathrm{x}}$ with a total thickness of $100 \mathrm{~nm}$.




This PPL and its encasing $\mathrm{SiO}_{\mathrm{x}}$ matrix are manufactured on the front surface of the silicon substrate. We present characterization of these layers demonstrating a PPL layer capable of yielding lower reflectivity than comparative optimum ARCs made from the matrix material.

A PECVD method is unsuitable because of the process temperature which is sufficient to adversely affect the MNP size distribution and geometry and hence the properties of the PPL. High temperatures furthermore present a metallic contamination risk for PECVD chamber systems.

This work proposes Hydrogen Silsesquioxane (HSQ) as an alternative. This is a flowable oxide commonly used for e-beam lithography which can be deposited by spin coating at room temperature. It has good surface coverage properties allowing it to homogeneously encase the MNPs and fill spaces between them. ${ }^{21}$ The HSQ may then be transformed into a layer with optical properties analogous to $\mathrm{SiO}_{x}$ with a single low temperature bake which does not adversely affect the PPL and the underlying solar cell.

Section II presents the fabrication of the structures studied. We then give a quantitative analysis of the optical response of the resulting layers showing a better response than standard ARCs as well as the final effect on a solar cell, exhibiting a considerable loss in the quantum efficiency due to Fano interference. ${ }^{22-24}$ We conclude with a discussion of these competing mechanisms.

\section{EXPERIMENTAL}

\section{A. Sample preparation}

c-Si polished $\langle 100\rangle$ p-type wafers with resistivity between 1 and $3 \Omega \mathrm{cm}$ are used to prepare $17 \times 17 \mathrm{~mm}^{2}$ substrate samples. All substrates are cleaned with acetone, iso-propyl alcohol (IPA), and de-ionized water. Once the native oxide is removed using diluted HF (2\%), silicon oxide $\left(\mathrm{SiO}_{\mathrm{x}}\right)$ of different thickness is deposited by PECVD in a reactor model P5000 Mark II of Applied Materials. The process gas used has been Tetraethyl Orthosilicate (TEOS) and oxygen as precursor. The thickness of the resulting layer is measured using a thin film analyser model Filmetrics F20.

Two different $\mathrm{Ag}$ thickness precursor layers are studied. $3 \mathrm{~nm}$ and $10 \mathrm{~nm}$ of $\mathrm{Ag}$ are evaporated on cleaned substrates using a Pfeiffer Classic-500 e-gun PVD and annealed in nitrogen ambient for $1 \mathrm{~h}$ at $200^{\circ} \mathrm{C}$ (for $3 \mathrm{~nm} \mathrm{Ag}$ precursor) or $300^{\circ} \mathrm{C}$ (for $10 \mathrm{~nm} \mathrm{Ag}$ precursor). These recipes have been optimized previously ${ }^{12,28}$ and lead to Ag MNPs suitable to be embedded into a $100 \mathrm{~nm}$ ARC. Samples of varying $\mathrm{SiO}_{\mathrm{x}}$ thickness with as-deposited $\mathrm{Ag}$ MNPs are subsequently spin coated in a EVG101 Advanced Resist Processing System with a HSQ resist from Dow Corning (ancient Fox ${ }^{\circledR} 12$ ). Where applicable, Methyl Iso Butil Ketone (MIBK) is used for resist dilution.

$\mathrm{A} \mathrm{SiO}_{\mathrm{x}}$ layer acts as an efficient ARC for silicon solar cells, with an optimum thickness of approximately $100 \mathrm{~nm}$ for an AMG1.5 solar spectrum. The optical properties of HSQ being similar to $\mathrm{SiO}_{\mathrm{x}}{ }^{25}$ there is no significant difference in reflectivity between $\mathrm{SiO}_{\mathrm{x}}$ or any combination of $\mathrm{SiO}_{\mathrm{x}}$ and HSQ if the total thickness is the same. Samples have been fabricated with the Ag PPL at different positions between $\mathrm{SiO}_{\mathrm{x}}$ and $\mathrm{HSQ}$, as summarized in Table I and shown in Figure 1 .

TABLE I. Position of Ag nanoparticles.

\begin{tabular}{|c|c|c|}
\hline Sample & $\varepsilon_{\mathrm{SiOx}}{ }^{\mathrm{a}}(\mathrm{nm})$ & $\varepsilon_{\mathrm{HSQ}}{ }^{\mathrm{b}}(\mathrm{nm})$ \\
\hline 1 & 0 & 100 \\
\hline 2 & 10 & 90 \\
\hline 3 & 30 & 70 \\
\hline 4 & 50 & 50 \\
\hline 5 & 70 & 30 \\
\hline 6 & 100 & 0 \\
\hline
\end{tabular}

\footnotetext{
${ }^{\mathrm{a}} \varepsilon_{\mathrm{SiOx}}$ is the thickness of $\mathrm{SiO}_{\mathrm{x}}$ underneath de $\mathrm{Ag}$ nanoparticles deposited by PECVD.

${ }^{\mathrm{b}} \varepsilon_{\mathrm{HSQ}}$ is the thickness of HSQ on de Ag nanoparticles deposited by spin-coating.
} 


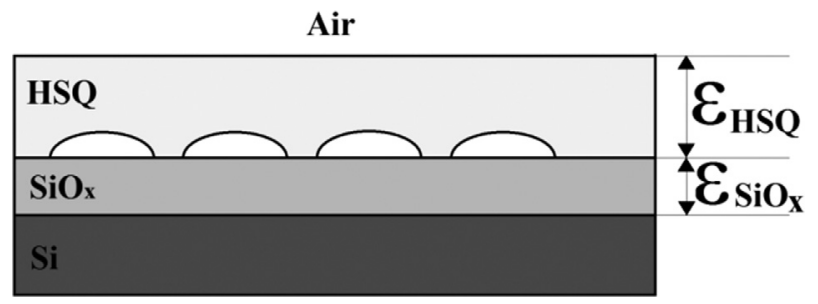

FIG. 1. Simplified structure of the PARC coating.

As the HSQ has to be baked, ${ }^{26}$ samples are further annealed for $1 \mathrm{~h}$ at the same temperature as during the previous annealing. It has been verified that this second annealing without HSQ does not significantly change the size and shape distribution of the Ag MNPs. Moreover, the HSQ, filling as it does the spaces between particles, prevents interaction between them. It can, therefore, be assumed that the size and shape distribution of the Ag MNPs within the plasmonic ARC (PARC) is constant.

\section{B. Size distribution analysis}

SEM analysis has been performed and Fiji image treatment software ${ }^{27}$ applied to the resulting micrographs. This determines the size of the resulting particles as well as the coverage properties of the HSQ on the Ag MNP. The analysis allows the fitting of an ellipse to particle shapes, thereby defining a major axis $\left(\mathrm{D}_{\mathrm{A}}\right)$ and a minor axis $\left(\mathrm{D}_{\mathrm{B}}\right)$ and corresponding area. From this total ellipsoidal area, an equivalent diameter of a particle $\left(\mathrm{D}_{\mathrm{EQ}}\right)$ can also be defined as the diameter of a circular particle with identical area. These particle parameters enable theoretical analysis in terms of extinction coefficient and absorption cross section of nanoparticles as a function of particle geometry.

\section{Reflectivity characterisation and comparison of samples}

The front surface reflectivity of the samples has been measured from 400 to $1100 \mathrm{~nm}$ using a $150 \mathrm{~mm}$ integrating sphere and a spectrophotometer from National Instrument model CAS $140 \mathrm{CT}$. In order to compare the antireflection properties of different surface coatings before considering the underlying solar cell, it is useful to develop a quantitative method of evaluation front surface reflectivity in terms of a single parameter. In order to do this, we use the definition of short circuit current $\mathrm{J}_{\mathrm{sc}}$ in terms of front surface reflectivity $\mathrm{R}$ as a function of wavelength and in terms of the internal quantum efficiency (IQE) of the cell

$$
J_{s c}=\frac{q}{h \times c} \cdot \int_{\lambda_{0}}^{\lambda_{N}} \operatorname{IQE}(\lambda) \times(1-R(\lambda)) \times \lambda \times A M_{1.5 G}(\lambda) d \lambda,
$$

where $q$ is the elemental charge of the electron in Coulombs, $h$ is Planck's constant, $c$ is the speed of light, $\lambda$ is the wavelength, $\mathrm{R}(\lambda)$ is the measured reflectivity, $A M 1.5 G$ is the standard solar spectral irradiance in $\mathrm{W} /\left(\mathrm{m}^{2} \mathrm{~nm}\right)$, and $\operatorname{IQE}(\lambda)$ is the quantum efficiency of the solar cell.

The IQE in Eq. (1) is defined as efficiency of carrier collected from the cell terminals relative to light transmitted through the front surface of the cell. This definition includes all losses apart from reflected or backscattered light: Transport losses in the semiconductor layers, all parasitic absorption losses in the structure (including absorption in the AR coat layers, absorption by the metal), and interference effects including Fano interference in the plasmonic layers. It therefore overestimates the transmission, since absorption cannot be determined explicitly. We discuss the absorption mechanisms in the PPL in more detail in the following sections. 
This simple procedure allows us to define an average reflectivity $R_{a v}$ defined as

$$
R_{a v}=\frac{\int_{\lambda_{0}}^{\lambda_{N}} R(\lambda) \times \lambda \times A M_{1.5 G}(\lambda) d \lambda}{\int_{\lambda_{0}}^{\lambda_{N}} \lambda \times A M_{1.5 G}(\lambda) d \lambda} .
$$

We evaluate $\mathrm{R}_{\mathrm{av}}$ in order to allow easier comparison between the different plasmonic ARC coatings and their effect on the final short-circuit current density. Inserting Eq. (2) in Eq. (1) and assuming an ideal cell where $\operatorname{IQE}(\lambda)=1$ for every wavelength, the short circuit current density becomes

$$
J_{s c}=J_{s c}^{\max } \times\left(1-R_{a v}\right),
$$

where

$$
J_{s c}^{\max }=\frac{q}{h \times c} \times \int_{\lambda_{0}}^{\lambda_{N}} \lambda \times A M_{1.5 G}(\lambda) d \lambda .
$$

This methodology defines a single metric characterising reflectivity as a function of ARCs in terms of potential short current densities. The following sections contrast this with short circuit current densities achieved in practise, allowing conclusions to be drawn concerning loss mechanisms mentioned earlier in the definition of IQE.

\section{Integration in a solar cell}

In order to study the effect of this PARC on a finished solar cell, the best configurations are tested on Interdigitated Back Contact (IBC) solar cells. ${ }^{28}$ The External Quantum Efficiency $(\mathrm{EQE})$ is measured using a QEW7 solar cell quantum efficiency measurement system from PV Measurements. The reference values are those with the initial ARC coating. The ARC is then partially removed with HF and the best PARC is tested on them.

\section{RESULTS}

\section{A. Size and shape distribution}

Figure 2 shows the statistics of the Ag PPL obtained using the $3 \mathrm{~nm}$ and the $10 \mathrm{~nm}$ precursor layer. The normal data cumulative distribution shows the behaviour of a normal distribution with the same average and standard deviation as the raw data. Thus for both $\mathrm{Ag}$ sizes, the minor axis $D_{B}$ and the equivalent diameter $D_{E Q}$ can be considered as normal distributions and the average is a representative value of the size. For the major axis $\mathrm{D}_{\mathrm{A}}$, there is a deviation because some of the particles may coalesce, resulting in a few large values of $\mathrm{D}_{\mathrm{A}}$. In this case, the median is taken as a more representative value. In Table II, the main statistics of the particle distribution are summarized, from where we conclude that with $3 \mathrm{~nm} \mathrm{Ag}$ precursor, the resulting particles are about $14 \mathrm{~nm}$ and more circular than with $10 \mathrm{~nm}$ of $\mathrm{Ag}$ precursor (in which case, the particles are about $55 \mathrm{~nm}$ average). These results are in agreement with the results by Yang et al. ${ }^{11}$

\section{B. Simulated properties of Ag MNPs}

The relationship between the size of the MNPs and their scattering and extinction cross sections is well known. ${ }^{6}$ Briefly, the scattering cross section increases with $\mathrm{V}^{2}$, where $\mathrm{V}$ is the volume of the MNP. The absorption, on the other hand, increases linearly with the volume. These competing mechanisms lead to the thumb rule that the bigger the MNP is, the more scattering and the less absorption is observed, independent of their shape, but analytically verified for round or elliptical shapes. 

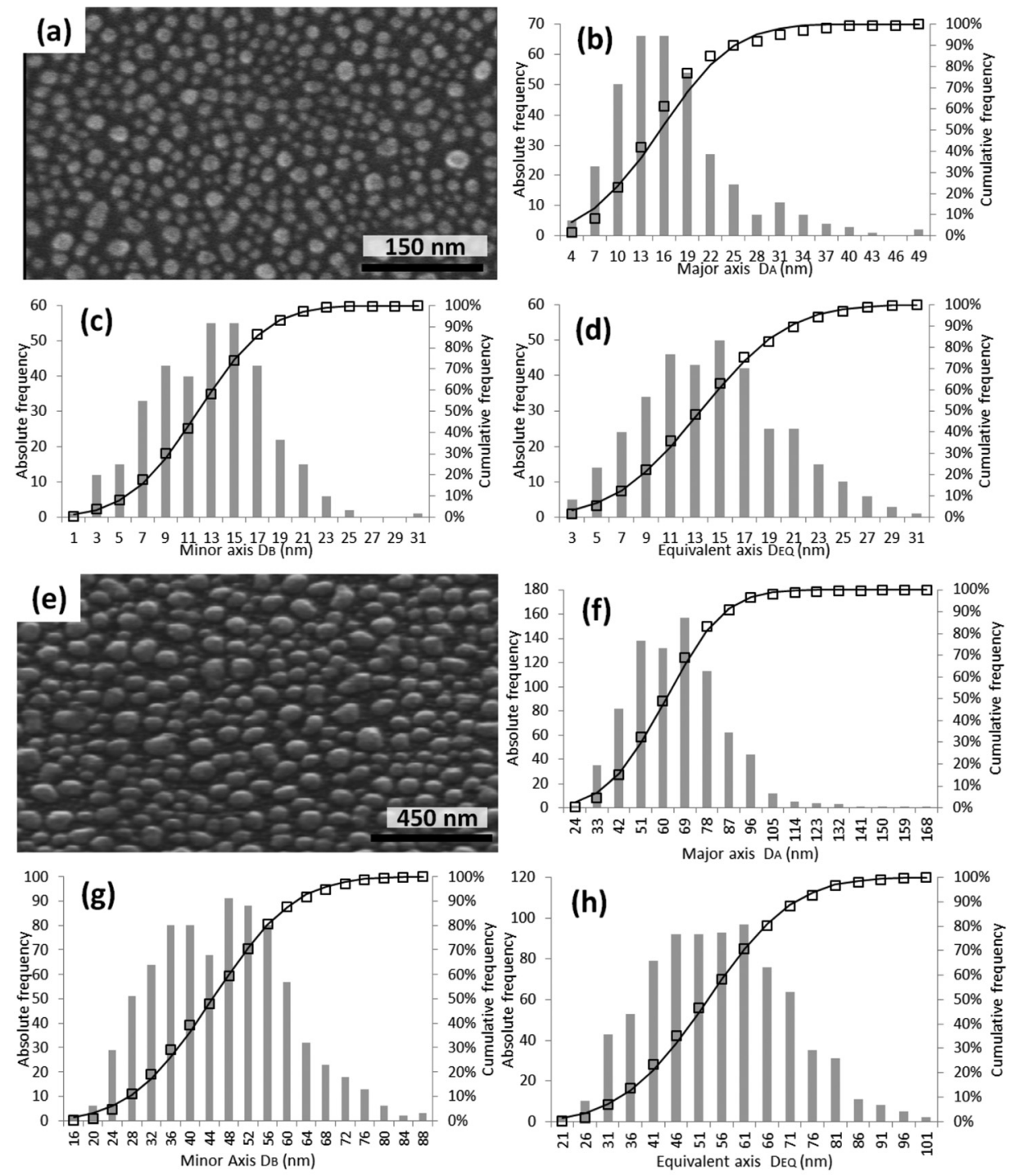

Absolute frequency $\square$ Data cumulative frequency -Normal cumulative frequency (\%)

FIG. 2. (a) SEM image of the Ag MNP self-aggregated from $3 \mathrm{~nm}$ of $\mathrm{Ag}$ precursor and their statistics for the major axis $\mathrm{D}_{\mathrm{A}}$ (b), minor axis $D_{B}$ (c), and equivalent axis $D_{\mathrm{EQ}}$ (d). (e) SEM image of Ag MNP self-aggregated from $10 \mathrm{~nm}$ of Ag precursor and their statistics for the major axis $\mathrm{D}_{\mathrm{A}}(\mathrm{f})$, minor axis $\mathrm{D}_{\mathrm{B}}(\mathrm{g})$, and equivalent axis $\mathrm{D}_{\mathrm{EQ}}(\mathrm{h})$.

For a single, spherical Ag particle of size D in a homogeneous medium of refractive index $\mathrm{n}$, it is possible to simulate the optical properties based on the exact analytic solution of Maxwell's equations. Figure 3 shows the absorption cross section and the albedo of different particles corresponding to the dimensions $\mathrm{D}_{\mathrm{A}}, \mathrm{D}_{\mathrm{B}}$, and $\mathrm{D}_{\mathrm{EQ}}$ defined in Sec. II. In the

TABLE II. Statistics of self-aggregated nanoparticles.

\begin{tabular}{lcc}
\hline \hline Ag precursor thickness & $3 \mathrm{~nm}$ & $10 \mathrm{~nm}$ \\
\hline Average minor axis $\mathrm{D}_{\mathrm{B}}(\mathrm{nm})$ & 13 & 47 \\
Average equivalent axis $\mathrm{D}_{\mathrm{EQ}}(\mathrm{nm})$ & 14 & 55 \\
Median major axis $\mathrm{D}_{\mathrm{B}}(\mathrm{nm})$ & 15 & 64 \\
Surface coverage $(\%)$ & 34 & 51 \\
Average distance between particles $(\mathrm{nm})$ & 8 & 12 \\
\hline \hline
\end{tabular}


modelling, ${ }^{29}$ a symmetric environment has been assumed with averaged refractive index of $\mathrm{n}_{\mathrm{av}}=1.9$ instead of $\mathrm{n}_{\mathrm{SiOx}}=1.45$ in order to take into account the high refractive index of the $\mathrm{Si}$ substrate. This value is obtained from usual ARC theory, ${ }^{30}$ as the geometric mean of the refractive indices between neighbouring layers

$$
n_{a v}=\sqrt{\left(\frac{n_{H S Q}}{n_{S i O x}}\right)^{2} \frac{n_{S i}}{n_{a i r}}} .
$$

The results presented in Fig. 3 allow drawing conclusions for the more complex structure of the PPL. There it is shown which portion of the light interacting with the MNPs is scattered and which is absorbed by the particles.

Optical properties arising from the coupling of differently sized, irregularly distributed particles can be deduced by comparison with simulations of random nanoparticle distributions, ${ }^{29}$ as discussed in Sec. IV.

\section{Influence of the relative position of the Ag MNPs on the reflectivity of the ARC}

Figure 4 shows contour plots of reflectivity as a function of sample type and wavelength. Figure 4(a) shows the reflectivity of different thicknesses of standard $\mathrm{SiO}_{\mathrm{x}} \mathrm{AR}$ coats on bare $\mathrm{Si}$. Figure 4(b) shows the reflectivity of PARC coats with $D_{\mathrm{EQ}}$ of $14 \mathrm{~nm}$ as a function of MNP position in the PARC, that is, of the $\mathrm{SiO}_{\mathrm{x}}$ thickness under the MNP layer. Figure 4(c) shows the equivalent data for PARC coats with $\mathrm{D}_{\mathrm{EQ}}$ of $55 \mathrm{~nm}$.

The data in Fig. 4(a) show as expected that the lowest reflectivity for a $\mathrm{SiO}_{\mathrm{x}}$ coat is obtained for $100 \mathrm{~nm}$ of $\mathrm{SiO}_{\mathrm{x}}$, the standard thickness for this type of single layer AR coat.

In the case of plasmonic nanoparticle integration, Fig. 4(b) shows that reflectivity can be reduced at long and at short wavelengths, depending on the position of the MNPs in the $\mathrm{SiO}_{\mathrm{x}}$ layer for the smaller MNP equivalent diameter. In particular, a MNP layer position at about $70 \mathrm{~nm}$ from the Si surface in the $100 \mathrm{~nm}$ PARC decreases reflectivity for wavelengths beyond

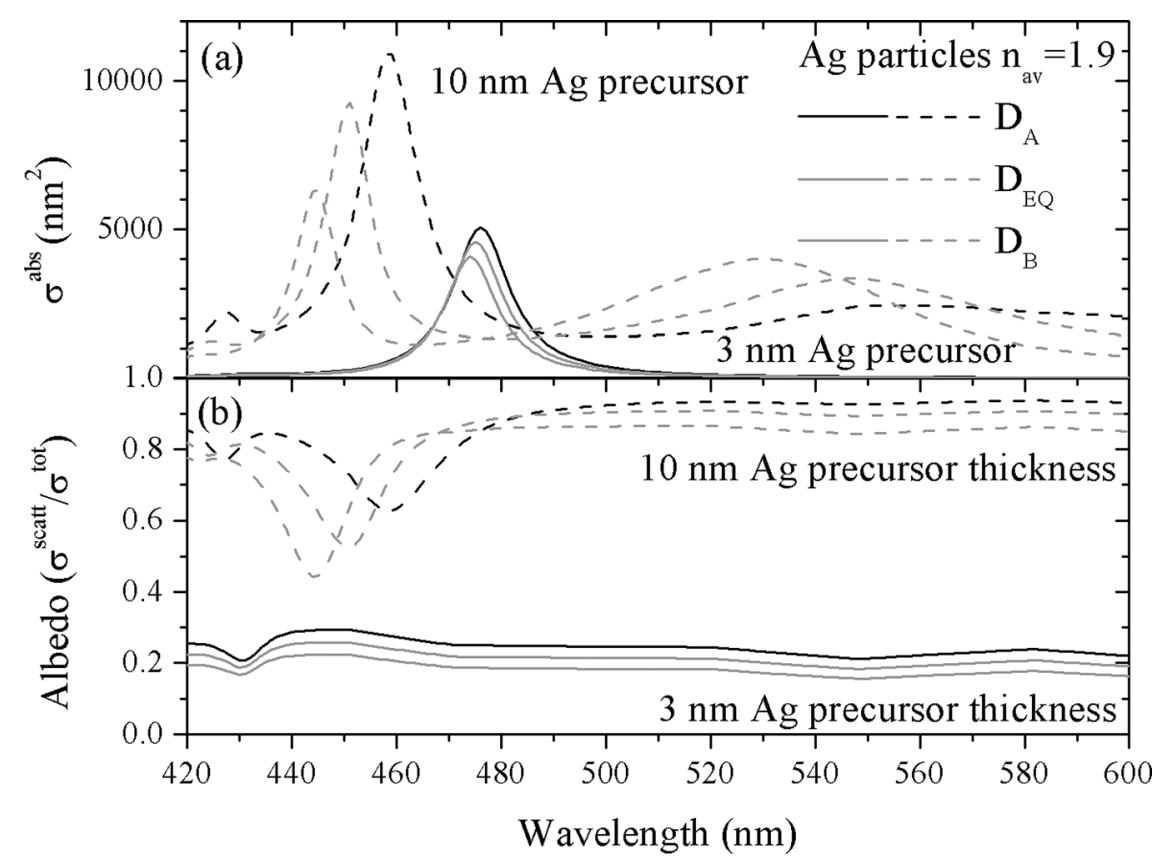

FIG. 3. (a) Simulated absorption cross section and (b) and simulated albedo. In both cases, a spherical shape has been assumed for Ag MNPs and the different diameters shown in Table II. A symmetric environment has been assumed with an averaged refractive index to take into account the higher index Si substrate. 

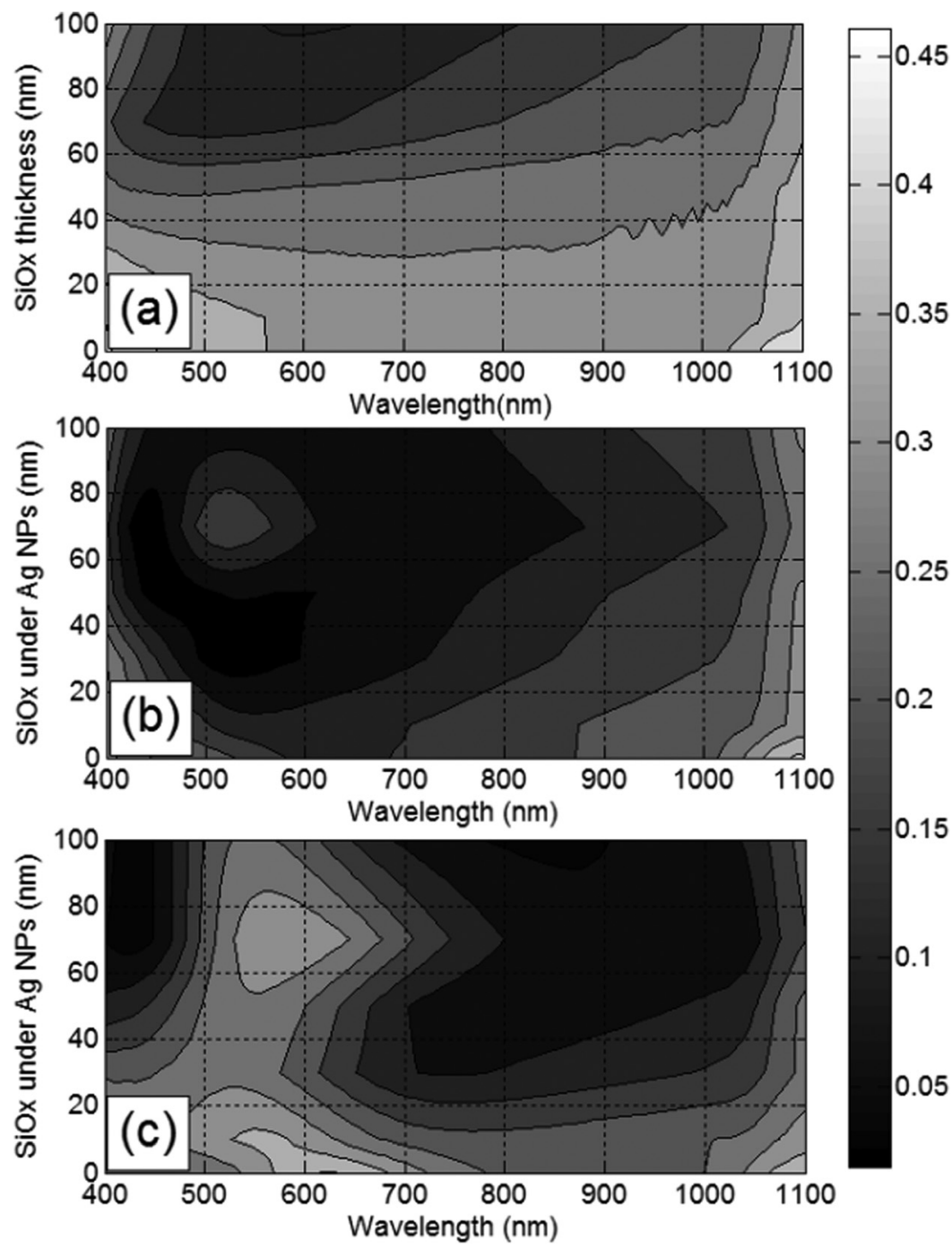

FIG. 4. (a) Contour plot for reflectivity of specular polished c-Si with different thicknesses of $\mathrm{SiO}_{\mathrm{x}}$ deposited as ARC. (b) Contour plot for the reflectivity of a $100 \mathrm{~nm} \mathrm{SiO} / \mathrm{Ag}$ MNPs PARC depending on the amount of $\mathrm{SiO}_{\mathrm{x}}$ underneath nanoparticles with $\mathrm{D}_{\mathrm{EQ}}$ of about $14 \mathrm{~nm}$. (c) Idem than (b) for $\mathrm{D}_{\mathrm{EQ}}$ about $55 \mathrm{~nm}$.

$600 \mathrm{~nm}$ and below about $500 \mathrm{~nm}$. Unfortunately, a reflectivity peak is observed in the region of the plasmon resonance.

The data for the larger MNPs of $55 \mathrm{~nm}$ in Figure 4(c) show similar trends more strongly. The infra-red and short wavelength reflectivity is decreased much more strongly, but the reflectivity peak in the vicinity of the plasmon resonance is significantly increased.

These data have been used to obtain values of $\mathrm{R}_{\mathrm{av}}$ in each case giving a reflectivity figure of merit covering the range from 400 to $1100 \mathrm{~nm}$. These results are shown in Figure 5. The reference levels are $R_{a v}$ values for polished silicon (upper) and flat silicon with an ARC of $100 \mathrm{~nm}$ of silicon oxide (lower). The PARC can make $\mathrm{R}_{\mathrm{av}}$ greater than polished silicon (as silver is more reflective than silicon) or, preferably, lower than the optimal $100 \mathrm{~nm}$ silicon oxide layer.

\section{Effect on the EQE}

The best PARC has been deposited on a IBC solar cell. Figure 5 shows that for both 3 and $10 \mathrm{~nm}$ of $\mathrm{Ag}$ precursors, the lowest Rav that can be achieved is about $10 \%$. Figure 4, however, shows that the reflectivity in the range of $600-700 \mathrm{~nm}$ is higher for the $10 \mathrm{~nm}$ sample. Equation (3) assumes an ideal 100\% IQE whereas the experimental IQE is wavelength dependent and 

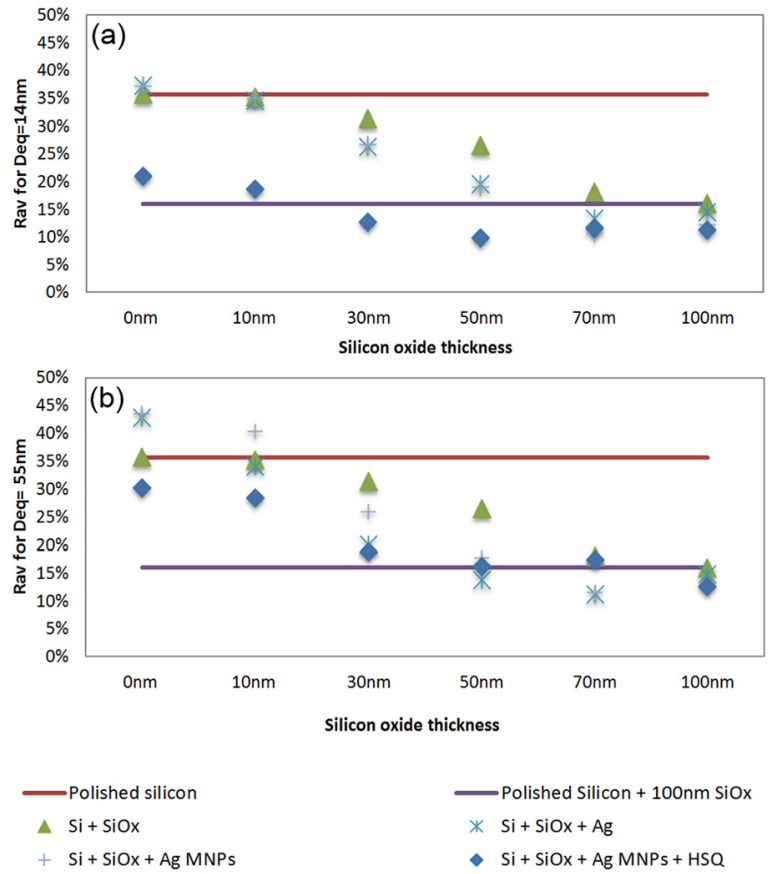

FIG. 5. (a) Average reflectivity for the samples summarized in Table I at different steps of fabrication using a $3 \mathrm{~nm} \mathrm{Ag} \mathrm{pre-}$ cursor. (b) Idem for $10 \mathrm{~nm}$ of Ag precursor. In both cases, the upper (red) line corresponds to the reflectivity of a specular polished bare c-Si substrate and the lower (purple) line to the reflectivity of a $100 \mathrm{~nm}$ layer of $\mathrm{SiO}_{\mathrm{x}}$ on a specular polished bare c-Si substrate.

peaks between 600 and $800 \mathrm{~nm}$. Therefore, the most promising PARC is the one using $3 \mathrm{~nm}$ of $\mathrm{Ag}$ precursor and $50 \mathrm{~nm}$ of HSQ since its reflectivity is significantly lower in the wavelength range where the experimental IQE is maximum. Consistently with this, an increase in the EQE due to increased scattering into the solar cell is seen at long wavelengths, which is the desirable effect of the Ag PPL. However, the EQE measurement (Figure 6) shows a considerable loss at short wavelength when Ag nanoparticles are included on the front side of the cell.

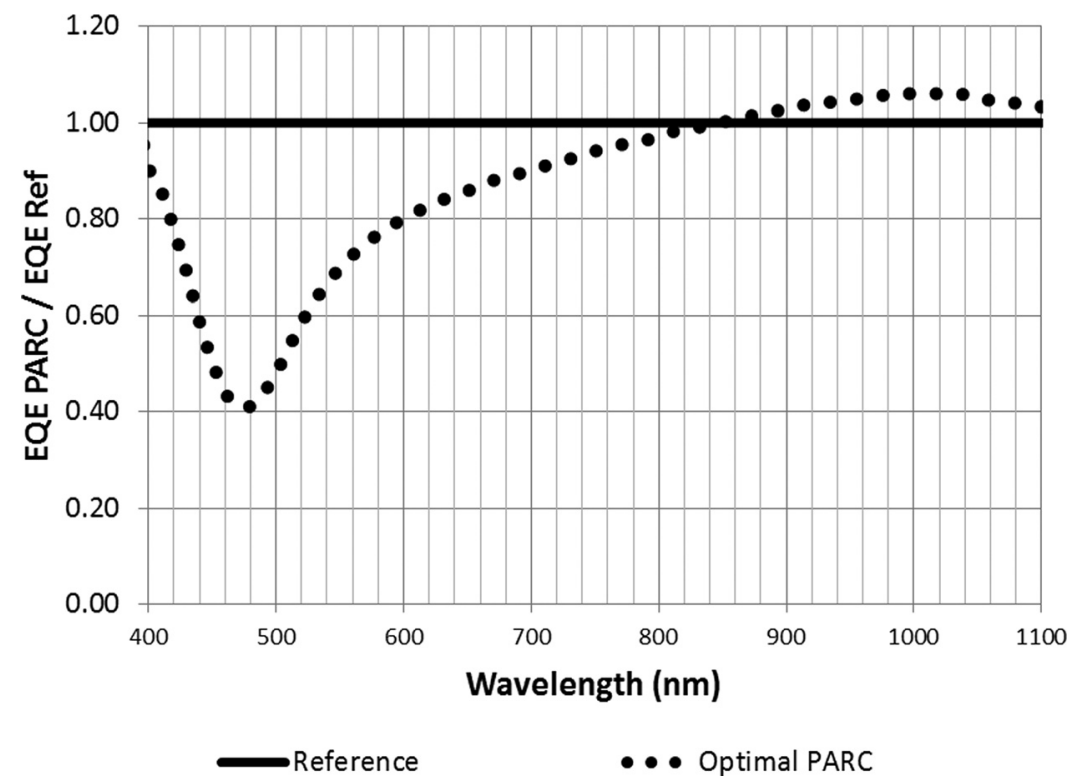

FIG. 6. Effect of different PARCs on the quantum efficiency of a solar cell. 


\section{DISCUSSION}

The data in Figure 4 show that the reflectance is reduced for a wide range of wavelengths and compositions with respect to the reference cell reflectivity. In general, larger the particles, the greater the overall reflectance of the PARC as quantified by $\mathrm{R}_{\mathrm{av}}$ tends to be. The particle density is not equivalent in both cases. As seen in Table II, the surface coverage is about $34 \%$ for $3 \mathrm{~nm} \mathrm{Ag}$ precursor MNPs and about $51 \%$ for $10 \mathrm{~nm} \mathrm{Ag} \mathrm{precursor} \mathrm{Ag} \mathrm{MNPs.} \mathrm{As} \mathrm{the} \mathrm{cover-}$ age increases, the reflectivity is increased, as silver is more reflective than silicon.

When HSQ is placed on the top of the Ag particles, reflectivity usually decreases. This reduction in the reflectivity is related to multiple factors.

First, as the Ag MNPs are covered by HSQ, light trapping ensures that the back scattered light is trapped in the HSQ (see Figure 7). As shown in Figure 3, the smaller particles scatter less efficiently and more absorbed light is lost to ohmic heating due to their small size. The larger particles, however, have an albedo $>80 \%$ for the whole considered spectrum and they scatter the incoming light more efficiently with only a small portion being absorbed, so there is an important back radiation that increases the reflection. That is why the contribution of the capping layer is especially important for larger particles. However, for some of the configurations shown in Table I, the HSQ does not fully cover the bigger nanoparticles from the $10 \mathrm{~nm}$ Ag precursor.

Another factor that reduces the reflectivity is the destructive interference that occurs at different coating thicknesses and that is expected to be diminished with increasing $\mathrm{SiO}_{\mathrm{x}}$ thickness underneath the particles. ${ }^{2}$

The investigated layers of Ag MNP are composed of a random distribution of hemispherical particles. As shown in Table II, particles obtained from $10 \mathrm{~nm}$ of $\mathrm{Ag}$ precursor have a broader variance in the particle shape dimensions than those from $3 \mathrm{~nm}$ of $\mathrm{Ag}$ precursor. This makes the radiated spectrum of the bigger particles broader as well. For this reason, it is difficult to find an optimum $\mathrm{SiO}_{\mathrm{x}}$ thickness for the larger particles in order to avoid the destructive interferences between layers. Regarding this point, Figure 5 shows that the best results in reflectivity for bigger particles are not necessarily those with the final HSQ coating giving a final $100 \mathrm{~nm}$ oxide layer. In the case of the smaller particles, as they are more homogeneous, this optimum is narrower and therefore is easier to define.

Furthermore, for the HSQ covered samples, $\mathrm{R}_{\mathrm{av}}$ is below the lower reference limit when the thickness of the silicon oxide layer under the Ag nanoparticles is similar or greater to the average size of the particle ( $15 \mathrm{~nm}$ for $3 \mathrm{~nm} \mathrm{Ag}$ precursor and $50-70 \mathrm{~nm}$ for $10 \mathrm{~nm} \mathrm{Ag}$ precursor). All this points towards an optimum configuration that can be found for different $\mathrm{Ag}$ precursor thicknesses. This conclusion is similar to what was reported by Pillai ${ }^{31}$ and Xu et al $^{32,33}$

As shown in Figure 3, particles with a small spread in shape barely modify the absorption cross sections and the absorption maximum. The Ag PPLs with bigger particles are less homogeneous and there is a high spread in size distribution and therefore circularity. This leads to a redshift of the cross sections as the diameter increases and a decrease in peak intensity.
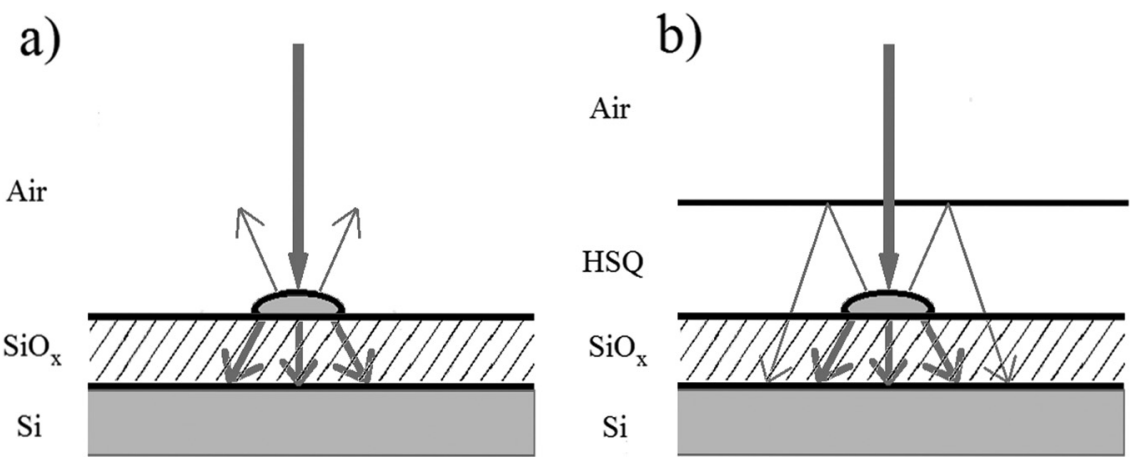

FIG. 7. Effect of mismatching of the refractive index that allows to reduce the reflectivity when an HSQ is put on the samples 


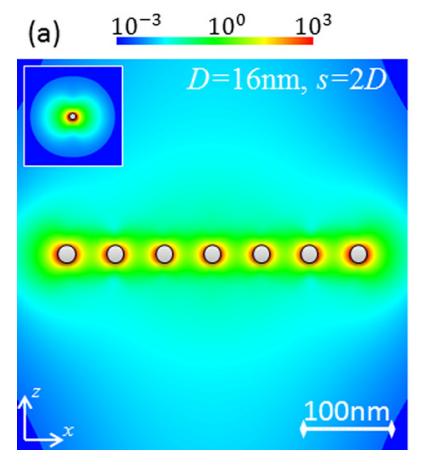

Near field maps $\left|E / E_{0}\right|^{2}$

(b) $10^{13} \quad 10^{15} \quad 10^{17}$
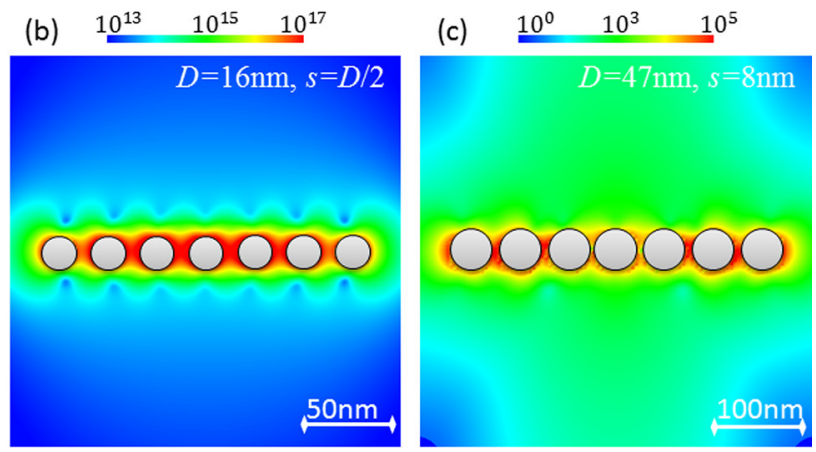

FIG. 8. Simulated near field intensity maps of Ag nanoparticles in a symmetric environment of $\mathrm{n}=2$ (no substrate) at a wavelength of $470 \mathrm{~nm}$. (a) For $\mathrm{D}=16 \mathrm{~nm}$ and a separation $\mathrm{s}=2 \mathrm{D}$, the generated fields are close to the case of an isolated sphere (inset). (b) Same size with a separation $\mathrm{s}=8 \mathrm{~nm}$ as found in the experiment. Strong local field enhancement is observed, creating hotspots in the volume between the nanoparticles. (c) For $\mathrm{D}=47 \mathrm{~nm}$ and $\mathrm{s}=8 \mathrm{~nm}$, the greater albedo is observed by strong scattering. At this separation, hot spots are created but with lower overall enhancement.

There is a difference between the position of the plasmonic resonance peaks in Figures 3 and 4. In Figure 3, the resonance has been calculated at $470 \mathrm{~nm}$ assuming that particles are embedded in a symmetric environment with an average refractive index of $n=1.9$, weighting the layers. Furthermore, spherical particles have been assumed, whereas the fabricated samples lead to hemispherical shapes. In Figure 4, the nanoparticles have a Si background at different distances so that the effect of this higher refractive index substrate on the behaviour of the Ag NPs does change during the experiment.

As seen in Fig. 4(c), the plasmonic peak of the Ag MNP is very apparent in the $10 \mathrm{~nm}$ precursor samples and is almost suppressed in the $3 \mathrm{~nm}$ precursor samples (Fig. 4(b)). As shown in Table II, the smaller particles are separated about $8 \mathrm{~nm}$ whereas the larger ones are separated about $12 \mathrm{~nm}$. In order to clarify this observation, electrodynamic calculations, ${ }^{29} \mathrm{sim}$ ilar to those of Figure 3 at the spherical particle resonance, were performed without a substrate in order to shed light on the phenomenological impact of inter-particle plasmon coupling (Figure 8). These calculations show the trends in scattering as a function of particle size and separation similar to those achieved experimentally. Figure 8(a) shows the case of small particles (diameter $\mathrm{D}=16 \mathrm{~nm}$ ) widely spaced (separation $\mathrm{s}=32 \mathrm{~nm}$ ), with little interaction between particles and high scattering amplitudes, which points towards optical properties similar to those of isolated particles (see the inset in Figure 8(a)). Figure 8(b) shows the same particles $(\mathrm{D}=16 \mathrm{~nm})$ more closely spaced $(\mathrm{s}=8 \mathrm{~nm})$, showing increased interaction and decreased scattering. Finally, Figure $8(\mathrm{c})$ shows larger particles $(D=47 \mathrm{~nm})$ with the same $8 \mathrm{~nm}$ spacing as in Figure 8(b), showing the strongest scattering amplitude overall.

Comparing this with the experimental reflectivities (Figure 4) shows striking consistency in losses associated with strong plasmon resonances versus gains due to increased scattering. First, the calculation of Figure 8(a) corresponding to data shown in Figure 4(b) shows a decreased plasmon resonance consistent with decreased inter-particle plasmonic coupling. Second, the decreased reflectivity in the infra-red shows the beneficial effect of the increased forwards scattering as illustrated by the scattering shown in the theoretical analogue of Figure 8(a).

Considering the case of closely spaced large particles achieved experimentally, Figure 4(c) first shows a stronger plasmon resonance consistent with the small inter-particle spacing for the analogous theoretical case of Figure 8(c) Second, Figure 4(c) shows a much reduced infra-red reflectivity compared with Figure 4(b), consistent with the greater scattering shown in the corresponding theoretical analogue of Figure 8(c).

The overall conclusion is that the trends in the contour plots of Figure 4 are consistent with behaviour expected from the modelling for these nanoparticle sizes. This work shows that small particles may increase forwards scattering to some extent while paying some penalty due to losses associated with the plasmon resonance. It further shows that larger particles increase 
the forward scattering efficiency but with a much greater penalty in losses associated with a stronger plasmon resonance.

From this analysis, we conclude that the overall impact of the PARC in Figure 6 shows that, in spite of the slight improvement in the infrared spectral response, ${ }^{27,34}$ the increased reflectance at short wavelengths (Figure 4) coupled with Fano interference loss near the plasmonic resonance peak prevents light to be effectively transmitted into the solar cell for a range of wavelengths. This results in a significant reduction of EQE of the cells and therefore of the Jsc of integrated devices. In this case, the presence of Fano interference phenomena in addition to reflectivity losses rules out the validity of Eq. (3) in estimating the short circuit current density due to the assumptions discussed earlier regarding this expression.

\section{CONCLUSION}

Plasmonic ARC layers based on silver nanoparticles and silicon oxide have been studied on specular polished c-Si solar cells. Important differences have been found depending on the relative position of nanoparticles in the silicon oxide layer as well as on their size. Some improvements in reflectivity have been found with specific configurations. However, the addition of the Ag nanoparticles in this front surface geometry introduces Fano destructive interferences that reduce the efficiency of the cell.

\section{ACKNOWLEDGMENTS}

The authors would like to thank the European Union framework 7th program for making this work possible via the LIMA project as well as to the following fellowships: The R\&D FPI-UPV (P.A.I.D. program of the Universitat Politécnica de Valencia) and the FPU by the Spanish Ministerio de Educación, Cultura y Deporte.

${ }^{1}$ A. Polman and H. A. Atwater, "Photonic design principles for ultrahigh-efficiency photovoltaics," Nature Mater. 11, 174-177 (2012).

${ }^{2}$ H. A. Atwater and A. Polman, "Plasmonics for improved photovoltaic devices," Nature Mater. 9, 205-213 (2010).

${ }^{3}$ A. Polman, "Plasmonics applied," Science 322, 868 (2008).

${ }^{4}$ W. L. Barnes, A. Dereux, and T. Ebbesen, "Surface plasmon subwavelength optics," Nature 424, 824-830 (2003).

${ }^{5}$ E. Ozbay, "Plasmonics: Merging photonics and electronics at nanoscale dimensions," Science 311, 189-193 (2006).

${ }^{6}$ K. R. Catchpole and A. Polman, "Plasmonic solar cells," Opt. Express 16, 21793-21800 (2008).

${ }^{7}$ V. E. Ferry, M. A. Verschuuren, H. B. T. Li, E. Ver-hagen, R. J. Walters, R. E. I. Schropp, H. A. Atwater, and A. Polman, "Light trapping in ultrathin plasmonic solar cells," Opt. Express 18, A237-A245 (2010).

${ }^{8}$ R. A. Pala, J. White, E. Barnard, J. Liu, and M. L. Brongersma, "Design of plasmonic thin-film solar cells with broadband absorption enhancements," Adv. Mater. 21, 3504-3509 (2009).

${ }^{9}$ K. Aydin, V. E. Ferry, R. M. Briggs, and H. A. Atwater, "Broadband polarization-independent resonant light absorption using ultrathin plasmonic super absorbers," Nat. Commun. 2, 517 (2011).

${ }^{10}$ J. Grandidier, D. M. Callahan, J. N. Munday, and H. A. Atwater, "Light absorption enhancement in thin-film solar cells using whispering gallery modes in dielectric nanospheres," Adv. Mater. 23, 1272-1276 (2011).

${ }^{11}$ C. Yang, G. Zhang, H. M. Li, and W. J. Yoo, "Localized surface plasmon resonances caused by Ag nanoparticles on SiN for solar cell applications," J. Korean Phys. Soc. 56, 1488-1491 (2010).

${ }^{12}$ J. P. Conolly, C. David, P. Rodrguez, A. Griol, P. Welti, L. Bellires, J. Ayucar, J. Hurtado, R. Lopez, G. Sanchez, and F. J. G. de Abajo, "Analysis of plasmonic nanoparticle fabrication techniques for efficient integration in photovoltaic devices," in Proceedings of the 25th European Photovoltaic Solar Energy Conference and Exhibition/5th World Conference on Photovoltaic Energy Conversion, Valencia, Spain, 6-10 September, 2010.

${ }^{13}$ Y. K. Hong, H. Kim, G. Lee, W. Kim, J. Park, J. Cheon, and J. Koo, "Controlled two dimensional distribution of nanoparticles by spin-coating method," Appl. Phys. Lett. 80, 844 (2002).

${ }^{14}$ O. M. Nayfeh, D. A. Antoniadis, K. Mantey, and M. H. Nayfeh, "Uniform delivery of silicon nanoparticles on device quality substrates using spin coating from isopropyl alcohol colloids," Appl. Phys. Lett. 94, 043112 (2009).

${ }^{15} \mathrm{~J}$. N. Munday and H. A. Atwater, "Large integrated absorption enhancement in plasmonic solar cells by combining metallic gratings and antireflection coatings," Nano Lett. 11, 2195-2201 (2011).

${ }^{16}$ K. C. Krogman, T. Druffel, and M. K. Sunkara, "Anti-reflective optical coatings incorporating nanoparticles," Nanotechnology 16, S338-S343 (2005).

${ }^{17}$ Z. Starowicz and M. Lipinski, "Antireflection TiOx coating with metal nanoparticles for silicon solar cells," in Proceedings of the 27th European Photovoltaic Solar Energy Conference and Exhibition, Frankfurt, 24-28 September (2012).

${ }^{18}$ M. D. McMahon, R. Lopez, H. M. Meyer III, L. C. Feldman, and R. F. Haglund, Jr., "Rapid tarnishing of silver nanoparticles in ambient laboratory air," Appl. Phys. B 80, 915-921 (2005).

${ }^{19}$ H. K. Singh, M. Mathew, A. Kottantharayil, and C. S. Solanki, "Plasmonic effect of silver nanoparticles sandwiched in silicon nitride and oxide structures for solar cell application," in Proceedings of the 27th European Photovoltaic Solar Energy Conference and Exhibition, Frankfurt, 24-28 September (2012). 
${ }^{20}$ V. Giannini, Y. Ferancescato, H. Amrania, C. C. Phillips, and S. A. Maier, "Fano resonances in nanoscale plasmonic systems: A parameter-free modeling approach," Nano Lett. 11(7), 2835-2840 (2011).

${ }^{21}$ A. E. Grigorescu, M. C. van der Krogt, C. W. Hagen, and P. Kruit. "10 nm lines and spaces written in HSQ, using electron beam lithography," Microelectron. Eng. 84(5-8), 822-824 (2007).

${ }^{22}$ U. Fano, "Effects of configuration interaction on intensities and phase shifts," Phys. Rev. 124, 1866-1878 (1961).

${ }^{23}$ F. J. Beck, A. Polman, and K. R. Catchpole, "Tunable light trapping for solar cells using localized surface plasmons," J. Appl. Phys. 105, 114310 (2009).

${ }^{24}$ D. M. Callahan, J. N. Munday, and H. A. Atwater, "Solar cell light trapping beyond the ray optic limit," Nano Lett. 12, 214-218 (2011).

${ }^{25}$ S. Lis, R. Dylewicz, J. Mysliwiec, A. Miniewicz, and S. Patela, "Application of flowable oxides in photonics," Mater. Sci. (Poland) 26(1), 189-194 (2008).

${ }^{26}$ M. Häffner, A. Haug, A. Heeren, M. Fleischer, H. Peisert, T. Chassé, and D. P. Kern, "Influence of temperature on HSQ electron-beam lithography," J. Vac. Sci. Technol. B 25(6), 2045 (2007).

${ }^{27}$ C. Chaverri Ramos, L. Ballières, J. P. Connolly, J. Ayucar, and G. Sánchez, "Efficiency enhancement in plasmonic IBC solar cells," in Proceedings of the 27th European Photovoltaic Solar Energy Conference and Exhibition, Frankfurt, 24-28 September (2012).

${ }^{28}$ M. A. Vázquez, J. P. Connoly, O. Cubero, G. Daly, A. Halm, R. Kopecek, V. d. Mihailetchi, E. Pérez, G. Pucker, G. Sánchez, and L. Pavesi, "Cost model for LIMA device," Energy Procedia 8, $443-448$ (2011).

${ }^{29}$ F. J. G. de Abajo, "Multiple scattering of radiation in clusters of dielectrics," Phys. Rev. B 60, 6086-6102 (1999).

${ }^{30}$ H. A. Macleod, Thin Films Optical Filters, 4th ed. (CRC Press, 2010).

${ }^{31}$ S. Pillai, F. J. Beck, K. R. Catchpole, Z. Ouyang, and M. A. Green, "The effect of dielectric spacer thickness on surface plasmon enhanced solar cells for front and rear side depositions," J. Appl. Phys. 109, 073105 (2011).

${ }^{32}$ R. Xu, X. Wang, W. Liu, L. Song, X. Xu, A. Ji, F. Yang, and J. Li, "Optimization of the dielectric layer thickness for surface-plasmon induced light absorption for silicon solar cells,” Jpn. J. Appl. Phys., Part 1 51(4), 42301 (2012).

${ }^{33}$ R. Xu, X. Wang, W. Liu, A. Ji, F. Yang, and J. Li, "Influence of the light trapping induced by surface plasmons and antireflection film in crystalline silicon solar cells," Opt. Express 20(5), 5061-5068 (2012).

${ }^{34}$ V. E. Ferry, M. A. Verschuuren, H. B. T. Li, R. E. I. Schropp, H. A. Atwater, and A. Polman, "Improved red-response in thin film a-Si:H solar cells with soft-imprinted plasmonic back reflectors," Appl. Phys. Lett. 95, 183503-3 (2009). 